UDC 577.213.32:577.217.5:577.218:577.29: 541.515

\title{
CLONING AND EXPRESSION OF RECOMBINANT PROTEIN OF SUMO, FUSED WITH BIOTIN ACCEPTOR PEPTIDE
}

\author{
Kulyyassov A.T. ${ }^{1}$, Ramankulov Ye.M. ${ }^{1}$, Ogryzko V.V. ${ }^{2}$ \\ ${ }^{1}$ National Center for Biotechnology \\ 13/5, Korgalzhyn road, Astana, 010000, Kazakhstan \\ akulyyasov@gmail.com \\ ${ }^{2}$ Institut Gustave Roussy \\ CNRS UMR8126, 94805, 39 Rue Camilles Desmoulin, Villejuif, France
}

\section{ABSTRACT}

Post-translation modifications by SUMO are involved in a plethora of biological processes, including cell proliferation. Since SUMOylation is an essential regulatory mechanism in signal transduction, violation of the processes associated with SUMOylation can lead to various diseases, including cancer.

We adopted the proximity utilizing biotinylation method, based on co-expression of recombinant proteins within a single cell: the protein of interest fused with the biotin ligase BirA and its partner with the biotin acceptor peptide (BAP). This co-expression allows for accurate quantitative assessment of the extent of the interaction of various molecules in vivo.

Using this approach, the aim of this work was to construct a new plasmid vector containing a SUMO gene fused with a BAP and to implement its expression in HEK293T cells.

Co-expression of the BAP-SUMO and BirA-HP1 $\gamma$ (BirA-HP1 $\alpha$ ) recombinant proteins in HEK293T cells resulted in protein biotinylation, which are SUMOylated proximal proteins (or interaction partners) of the proteins of interest BirA-HP1 $\gamma$ and BirA-HP1 $\alpha$.

Key words: protein-protein interactions, biotinylation, biotin ligase, biotin acceptor peptide, plasmids, transient transfection, western blot, SUMO.

\section{INTRODUCTION}

The proteins inside the cell, after the translation process, are often subjected to covalent modification, which allows them to regulate their activity, localization or stability. Among the many known agents (or modifiers) involved in post-translational modifications (PTM) of protein substrates, there are also other proteins, mainly ubiquitin or ubiquitin-like proteins (UBLs). They are similar to each other (figure 1), both in structure and in the mechanism of enzymatic activation and attachment to the substrate [1].

Small ubiquitin-like modifier (SUMO) proteins are conjugated as a post-translational modification to more than a thousand proteins within mammalian cells [2-5]. All eukaryotes express at least one type of the SUMO protein family, but most mammals express three SUMO proteins. Although in some cases functional redundancy exists among multiple SUMO family members, the process of sumoylation is essential in nearly all eukaryotes [6]. SUMO proteins are involved in the regulation of many cellular functions, ranging from transcription regulation and chromatin remodeling to DNA repair and control of cell cycle progression [7-12]. SUMOs have been gaining popularity as therapeutic targets, with clinical potential in cancer and Alzheimer disease [7, 13, 14].

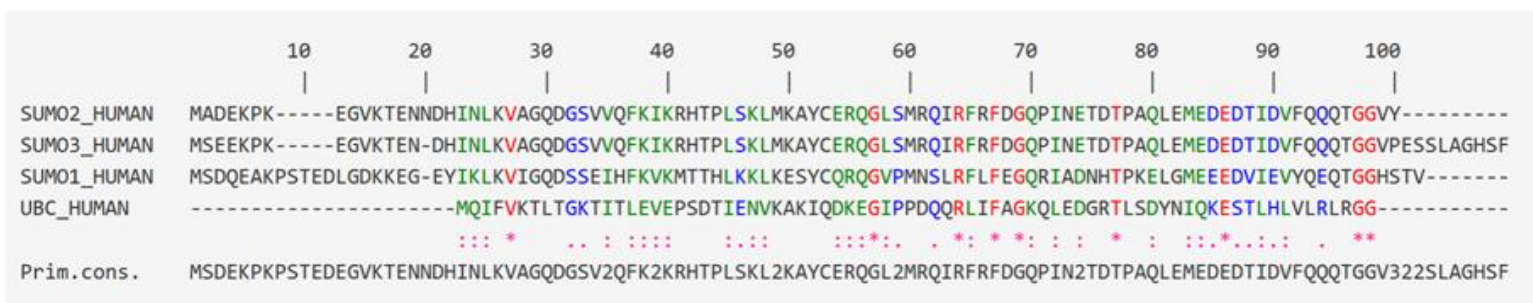

$20 \%$ sequence identity of ubiquitin and SUMO. SUMO1 and SUMO2 (50\% sequence identity). SUMO2 and SUMO3 ( $97 \%$ sequence identity)

Fig. 1. Alignment of aminoacid sequences of ubiquitin and SUMO proteins 
In humans, SUMO1, SUMO2 and SUMO3 are the main SUMO family members; they are often classified as SUMO1 and SUMO2/3 [15], as mature SUMO2 and SUMO3 are virtually identical (figure 1). Tertiary structures of ubiquitin and SUMO family proteins are similar despite some differences in sequence identity. For example $20 \%$ sequence identity of ubiquitin and SUMO1, 50\% sequence identity between SUMO1 and SUMO2, 97\% sequence identity between SUMO2 and SUMO3. All SUMO proteins are conjugated by the same enzymatic machinery, in a reversible manner [15]. SUMOs, like ubiquitin, are able to multimerize, forming polymeric chains [16-18]. The formation of these SUMO chains is substantiated by cellular stress conditions, such as heat shock [2].

Whereas ubiquitylation, acetylation and phosphorylation modify proteins throughout the cell, sumoylation occurs predominantly in the nucleus, especially at the chromatin and in nuclear bodies. Indeed, sumoylation is widely involved in the DNA-damage response (DDR) [8, 10], regulating DDR proteins such as G/T mismatchspecific thymine DNA glycosylase (TDG), proliferating cell nuclear antigen (PCNA), breast cancer type 1 susceptibility protein (BRCA1).

A review of the literature indicates that the enzymes involved in sumoylation can be suitable targets in cancer therapy. The use of new approaches for monitoring in vivo SUMOylation will, in the future, create new inhibitors of the key components of this system.

The development of methods that allow identifying certain key components of the SUMOylation system, responsible for the emergence of various pathologies will help in effective and quick selection of the appropriate medicine.

In this regard, studies on the development of methods that allow quantitative evaluation of expression and protein-protein interactions involving SUMO proteins are of current interest.

One of the advantages of the PUB method is possibility to quantify the degree of interaction of two proteins within the nuclei of eukaryotic cells in comparison with a control protein or control sample, both by available Western blotting method and liquid chromatography-tandem mass spectrometry LC-MS/MS.

\section{MATERIALS AND METHODES}

\section{Preparation of plasmid constructs containing the SUMO gene}

Design of primers containing N-, or C-terminal part of SUMO genes and XhoI or NotI restriction sites for subcloning to vector pcDNA3.1(+).BAP.

Primers (Restriction sites XhoI and NotI underlined):

Primer 1 SUMO1:

\section{CACACACACTCGAGATGTCTGACCAGGAGGCAAAACCTTCAACTGAGGACTT}

Primer 2 SUMO1 AS:

TGTGTGTGCGGCCGCTAAACTGTTGAATGACCCCCCGTTTGTTCCTGATAAA

Primer 1 SUMO3:

CACACTCGAGATGTCCGAGGAGAAGCCCAAGGAGGGTGTGAAGACAGAGAATGACCACAT

Primer 2 SUMO3 AS:

TGTGTGTGCGGCCGCTAGAAACTGTGCCCTGCCAGGCTGCTCTCCGGCACACCTCCCGTCTGCTGT TGGAACACGTCGATGGTGTCC

Plasmids pBBHN.SUMO1 and pBBHN.SUMO3 were used as matrixes for PCR amplification of SUMO1 and SUMO3 correspondingly. Amplicons after PCR were subcloned into pcDNA3.1(+).BAP vector. PCR conditions: denaturation $94^{\circ} \mathrm{C}-15 \mathrm{sec}$, annealing $54^{\circ} \mathrm{C}-30 \mathrm{sec}$, elongation $72^{\circ} \mathrm{C}-1 \mathrm{~min}$, number of cycles -20 .

Mix 1. Primers (Primer 1, Primer 2, $100 \mu \mathrm{M})-0.5 \mu \mathrm{l}$, DNA matrix $(100 \mathrm{ng})-0.5 \mu \mathrm{l}, \mathrm{H}_{2} \mathrm{O}-18.5 \mu \mathrm{l}$, dNTP $(2,5$ $\mathrm{mM})-5.0 \mu \mathrm{l}$. Total $-25.0 \mu \mathrm{l}$.

Mix 2. PCR buffer with $\mathrm{KCl}(5 \mathrm{x})-10.0 \mu \mathrm{l}, \mathrm{MgSO}_{4}(25 \mathrm{mM})-10.0 \mu \mathrm{l}$, Pwo DNA polymerase (Roche, 11644 $947001)-1.0 \mu \mathrm{l}(5 \mathrm{U} / \mu \mathrm{l}), \mathrm{H}_{2} \mathrm{O}-4.0 \mu \mathrm{l}$. Total $-25.0 \mu \mathrm{l}$.

Tubes with mixes 1 and 2 were combined, vortexed, spinned and loaded to PCR machine. Purification and desalting of PCR products was performed using Millipore kit according to manufacturer's instructions.

Plasmid pcDNA3.1(+).BAP.H2Az $(1 \mu \mathrm{g})$ which was used as a source of vector pcDNA3.1(+).BAP and PCR products containing SUMO amplicons were subjected to restriction by XhoI and NotI (20 e.a. in $20 \mu \mathrm{l}$ reaction mix) in corresponding buffers at $37^{\circ} \mathrm{C}$ during $2 \mathrm{hr}$. All following steps including gel electrophoresis, staining by ethidium bromide and excision of bands from agarose gel were carried out by standard protocol [19]. Purified vector and DNA fragments were ligated by T4 DNA ligase overnight at $4{ }^{\circ} \mathrm{C}$.

Plasmids with inserted UBL genes - pcDNA3.1(+).BAP.SUMO1 or pcDNA3.1(+).BAP.SUMO3 were obtained after bacterial transformation using competent cells DH5 $\alpha$ strain of E. coli. Endotoxin free vectors were purified using kits for preparation of plasmid DNA (Sigma, PLED35-1KT or Qiagen, 12362), according to protocols in manuals or instructions downloaded from the sites of Sigma or Qiagen.

\section{Sequencing of plasmids}

Primary structure of DNA was determined using BigDye v.3.1 kits (Life technologies, 4337455) on automatic DNA analyzers AB3730xl (Applied Biosystems) with primers pcDNA3.1_FP (5' CTCTGGCTAACTAGAGAAC 3') and primer2EMC (5' AGACGGCAATATGGTGGA 3'). 
Mix for 1 tube contained next components: $2.5 x$ Ready Reaction premix $-2 \mu l, 5 x$ BigDye Sequencing Buffer $-3 \mu \mathrm{l}$, primer $-5 \mathrm{pcmol}$, DNA matrix $-200 \mathrm{ng}$, water $-14 \mu \mathrm{l}$, total volume $20 \mu \mathrm{l}$.

Forward primer - pcDNA3.1-FP

5' CTCTGGCTAACTAGAGAAC 3' $\left(\mathrm{Tm}-49.0^{\circ} \mathrm{C}\right)$

Reverse primer - primer2EMC

5' AGACGGCAATATGGTGGA 3' $\left(\mathrm{Tm}-53.5^{\circ} \mathrm{C}\right)$

PCR program

$2 \min 96^{\circ} \mathrm{C}$

$10 \sec 96^{\circ} \mathrm{C}$ (denaturation)

$5 \sec 50^{\circ} \mathrm{C}$ (annealing)

4 min $60^{\circ} \mathrm{C}$ (elongation), 25 cycles

Purification of the products after PCR was carried out by precipitation with ethanol $(90 \%, 120 \mu \mathrm{l})$ and sodium acetate $(3 \mathrm{M}, 2 \mu \mathrm{l})$. After precipitation tubes were mixed, spinned $45 \mathrm{~min}$ at $7000 \mathrm{rpm}$ and supernatant was discarded. Pellet was washed by $140 \mu \mathrm{l}$ of $70 \%$ ethanol, spinned $15 \mathrm{~min}$ at $7000 \mathrm{rpm}$ and supernatant was discarded. The precipitate was then left for 15 minutes in the dark to remove ethanol. At the last stage, $14 \mu \mathrm{l}$ formamide (Hi-Di, Applied Biosystems) was added to the tubes, left for 5-10 minutes, denatured at $95{ }^{\circ} \mathrm{C}$ for 2 minutes, cooled on ice for 5 minutes. Samples were transferred to sequence plates (empty cells must be filled with $14 \mu$ formamide). Sequencing was carried out on a sequence analyzer from Applied Biosystems AB 3730xl DNA Analyzer (National Scientific Shared Laboratory of Biotechnology of the National Center for Biotechnology of the Republic of Kazakhstan, NSSLB NCB RK). Molecular genetic design and analysis of DNA sequencing results were carried out using the freely available program MEGA4.

Transient transfection of HEK293T cells

Expression of the recombinant proteins from the resulting plasmids was performed in HEK293T (Human embryonic kidney cells) cells using a calcium phosphate method.

To prepare the medium, $50 \mathrm{ml}(10 \%)$ of fetal bovine serum (FBS) and $5 \mathrm{ml}(1 \%)$ of a mixture of antibiotics streptomycin and ampicillin were added to $500 \mathrm{ml}$ of DMEM medium with a glucose content of $1 \mathrm{~g} / \mathrm{ml} \mathrm{or} 4.5 \mathrm{~g} / \mathrm{ml}$. A tube with HEK293T cells, after extraction from a Dewar vessel with liquid nitrogen, was rapidly thawed at $37^{\circ} \mathrm{C}$, centrifuged for 3 minutes at $200 \mathrm{rcf}$, and the supernatant removed. Then $10-15 \mathrm{ml}$ of pre-heated at $37^{\circ} \mathrm{C} \mathrm{DMEM}$ medium was poured into T75 culture flasks. The cells were then resuspended in DMEM medium, transferred to T75 flask and incubated at $37^{\circ} \mathrm{C}\left(\mathrm{CO}_{2}\right.$ content: $\left.4.8 \%\right)$.

To conduct the passage of HEK293T cells, a DMEM medium was at first preheated to $37^{\circ} \mathrm{C}$. Then, the old DMEM medium was removed by vacuum aspiration and $40 \mathrm{ml}$ of fresh medium was added to the cells. After this, the cells were resuspended and dispensed into 4 dishes $(10 \mathrm{ml}$ each). The cells were uniformly distributed over the surface of the plates, tilting them in perpendicular directions, and placed in an incubator at $37^{\circ} \mathrm{C}$.

A buffer solution of HBS 2x $(200 \mathrm{ml})$ was used for the transfection, consisting of the following components: Hepes $2 \mathrm{~g}, \mathrm{KCl} 0.15 \mathrm{~g}$, glucose $0.4 \mathrm{~g}, \mathrm{NaCl} 3.2 \mathrm{~g}, \mathrm{Na}_{2} \mathrm{HPO}_{4} 0.0426 \mathrm{~g}$ (pH is 5.9, adjusted to $\mathrm{pH} 7.0$ by addition in small portions of $1 \mathrm{M} \mathrm{NaOH}$ solution, then filtered through a sterile filter from Millipore and stored at $4{ }^{\circ} \mathrm{C}$ ).

A CSK buffer solution consisting of the following components was used to isolate the nuclei: $100 \mathrm{mM} \mathrm{NaCl}$, $300 \mathrm{mM}$ sucrose, $10 \mathrm{mM}$ Tris, $\mathrm{pH} 7.5,3 \mathrm{mM} \mathrm{MgCl}_{2}, 1 \mathrm{mM}$ EGTA, $1.2 \mathrm{mM}$ PMSF, 5mM iodoacetamide, $0.5 \%$ Triton X-100.

For the protein electrophoresis, a $3 \mathrm{x}(10 \mathrm{ml})$ loading buffer was used, which consists of the following components: $2.4 \mathrm{ml}$ of $1 \mathrm{M}$ Tris, $\mathrm{pH}$ 6.8, $0.8 \mathrm{~g}$ of SDS, $4 \mathrm{ml}$ of glycerol, $0.01 \%$ of bromophenol blue, $1 \mathrm{ml}$ of betamercaptoethanol and $2.8 \mathrm{ml}$ of water.

For the transfection of HEK293T cells, a calcium phosphate method was used [20]. At first, 200,000 HEK293T cells were seeded in each well of 6 well plates in $2 \mathrm{ml}$ of DMEM medium containing $10 \%$ of fetal bovine serum and $1 \%$ of a mixture of antibiotics of penicillin and streptomycin 1 day prior to transfection. The next day, 1 hour before transfection, the medium was changed, to $2 \mathrm{ml}$ of fresh DMEM. To carry out the transfection per 1 well, two $1.5 \mathrm{ml}$ tubes labeled $0 \mathrm{~A}, 0 \mathrm{~B}$ (1A, 1B or $2 \mathrm{~A}, 2 \mathrm{~B})$ were prepared. In one tube (Solution A), $220 \mu \mathrm{l}$ of water, $31 \mu \mathrm{l}$ of a $2 \mathrm{M}$ calcium chloride solution and the calculated amount of plasmid DNA $(0.5 \mu \mathrm{g}$ CMV.BAP.X, where $\mathrm{X}$ is UbC, SUMO1 or SUMO3 and 0.1 $\mu$ g CMV.BirA.Y, where Y - HP1a or HP1g). The second test tube (solution B) was loaded with $250 \mu$ l HBS $2 x$ buffer solution. A solution A was then slowly added dropwise to solution B, allowed to stand for 15 minutes, and then the resulting mixture was added to the HEK293T cells.

The next day, the medium was changed to fresh DMEM. Before cell lysis and isolation of nuclei (15 min), biotin pulse labeling was performed by adding medium containing $10 \mu \mathrm{lof}$ biotin $(1 \mathrm{mg} / \mathrm{ml})$ and $100 \mu 1$ of $50 \mathrm{mM}$ HEPES (pH 7.35) in $2 \mathrm{ml}$ of DMEM. The final concentration of biotin in the medium was $5 \mu \mathrm{g} / \mathrm{ml}$. Cells were harvested after 48 hours, the medium was removed, and then $1 \mathrm{ml}$ of PBS solution was added, resuspended and transferred to a $1.5 \mathrm{ml}$ tube. The tubes were then centrifuged at $+4{ }^{\circ} \mathrm{C}, 700 \mathrm{rcf}, 5$ minutes, the supernatant was removed and $100 \mu \mathrm{l}$ of CSK buffer containing $0.5 \%$ triton was added to cells, then pipetted several times, and centrifuged for 5 minutes at $4000 \mathrm{rpm}$. As a result, at this stage, HEK293T cell nuclei were obtained, which could be either frozen to $-20^{\circ} \mathrm{C}$ or immediately mixed with $80 \mu \mathrm{l}$ of CSK buffer without triton, subjected to sonication (to break down the genomic DNA and reduce viscosity) and mixed with $40 \mu$ l of loading buffer $3 \mathrm{X}$. The tubes were vortexed, heated at $98^{\circ} \mathrm{C}(5$ minutes $)$ and spinned in a mini-centrifuge at maximum speed. Analysis of the nuclear lysates by immunoblotting was performed according to the standard procedure [21]. 


\section{Electrophoresis of samples after transfection and Western blotting}

The day before the protein electrophoresis, glass cassettes (BioRad, 165-8000) with polyacrylamide gels (gel thickness $1.0 \mathrm{~mm}$ ) were prepared. Calculation of components for $12 \%$ polyacrylamide gel (separating gel) per 1 cassette: Acrylic/Bisacryl (30\%) $4.0 \mathrm{ml}$, TrisHCl, 1.5M, pH $8.8-2.5 \mathrm{ml}, \mathrm{H}_{2} \mathrm{O}-3,4 \mathrm{ml}, 10 \%$ SDS $100 \mu 1,10 \%$ APS $50 \mu \mathrm{l}$, TEMED $5 \mu \mathrm{l}$. Calculation of components for $4 \%$ polyacrylamide gel (concentrating gel) per 1 cassette: Acrylic / Bisacryl (30\%) $0.65 \mathrm{ml}$, TrisHCl, 0.5M, pH6.8 -1.25 ml, $\mathrm{H}_{2} \mathrm{O}-3.05 \mathrm{ml}, 10 \%$ SDS $50 \mu \mathrm{l}, 10 \%$ APS $50 \mu \mathrm{l}$, TEMED $10 \mu \mathrm{l}$.

Then $10 \mu \mathrm{l}$ of samples were loaded onto the gel, the chamber was filled with an electrode buffer solution $(30 \mathrm{~g}$ of Tris, $144 \mathrm{~g}$ of glycine and $10.5 \mathrm{~g}$ of SDS were taken per 1 liter of $10 \times$ solution) and run at a voltage of 100 volts for 120 minutes. A colored mixture of proteins from 10 to $250 \mathrm{kDa}$ (Fermentas, 26619) was used as a molecular marker. After the end of electrophoresis, the gel cartridge was pulled out of the chamber, it was opened and the gel was carefully transferred to a nitrocellulose membrane (Amersham Biosciences, 0.45 micron, RPN303c). The cassette for the immunoblot was placed in a special chamber, a transfer buffer was poured into it $(1 \mathrm{~g}$ of $1 \mathrm{x}$ solution was taken with $3 \mathrm{~g}$ of Tris, $14.4 \mathrm{~g}$ of glycine $1.5 \mathrm{~g}$ of SDS and $200 \mathrm{ml}$ of ethanol) to the required level, connected to a power supply and run at a voltage of 100 volts and a current of $350 \mathrm{~mA}$ for 110 minutes. At the end of the transfer, the membrane was blocked using a solution containing PBS, 0.2\% Tween and 5\% milk and left overnight with stirring on the shaker at $+14^{\circ} \mathrm{C}$.

Next day, the membrane was washed three times with $15 \mathrm{ml}$ of PBS solution with $0.2 \%$ Tween. Then $10 \mathrm{ml}$ of PBS $0.2 \%$ Tween and $2 \mu 1$ streptavidin-HRP (Invitrogen, 43-4323) or anti-His-HRP (QiaGen, 34460) were added and mixed on the shaker for 45 minutes. After treatment with the streptavidin-HRP (or anti-His-HRP) membrane, it was washed twice with $10-15 \mathrm{ml}$ of PBS $+0.5 \mathrm{M} \mathrm{NaCl}$ solution $(10 \mathrm{~min})$ and twice with $10-15 \mathrm{ml}$ of PBS solution without $\mathrm{NaCl}(15 \mathrm{~min})$. The membrane was treated with a mixture of $500 \mu \mathrm{l}$ Luminol / enhancer solution and $500 \mu \mathrm{l}$ Stable peroxide buffers (Applichem, A3417, 1200). Membranes were transefered in a thin transparent polyethylene film and placed in a cassette with a film (in the dark) to detect the signals of tagged proteins. To obtain a distinct picture, a film was held on the membrane with a threefold increase in the exposure time $(5,15,45$, and 135 seconds). The film was developed on a developing machine.

\section{RESULTS AND DISCUSSIONS}

The goal of this work was to obtain preliminary information on proximal (or interacting) UBL-modified (like Ub, SUMO1 or SUMO2/3) partners of the protein of interest (POI) in the nuclei of human eukaryotic cells using the method of proximity utilizing biotinylation (figure 2) [22-24]. To achieve this goal we planned the following main tasks. Firstly, we designed and constructed 2 new plasmids (pcDNA3.1(+).BAP.SUMO1 and pcDNA3.1(+).BAP.SUMO3) and checked them by sequencing. Secondly, we used these vectors for coexpression of BAP-SUMO1 and BAP-SUMO3 together with BirA-HP1 $\gamma$ or BirA-HP1 $\alpha$ in HEK293T cells. Vector pcDNA3.1(+).BAP.UbC which we obtained earlier [25] was used in these experiments for comparison. As protein of interest we selected paralogues of heterochromatin proteins (HP1 $\alpha$ and HP1 $\gamma$ ). In mammalian cells these proteins have been implicated in gene silencing, genome stability, chromosome segregation and also HP1 $\alpha$ can be used as prognostic marker of cancer [24].

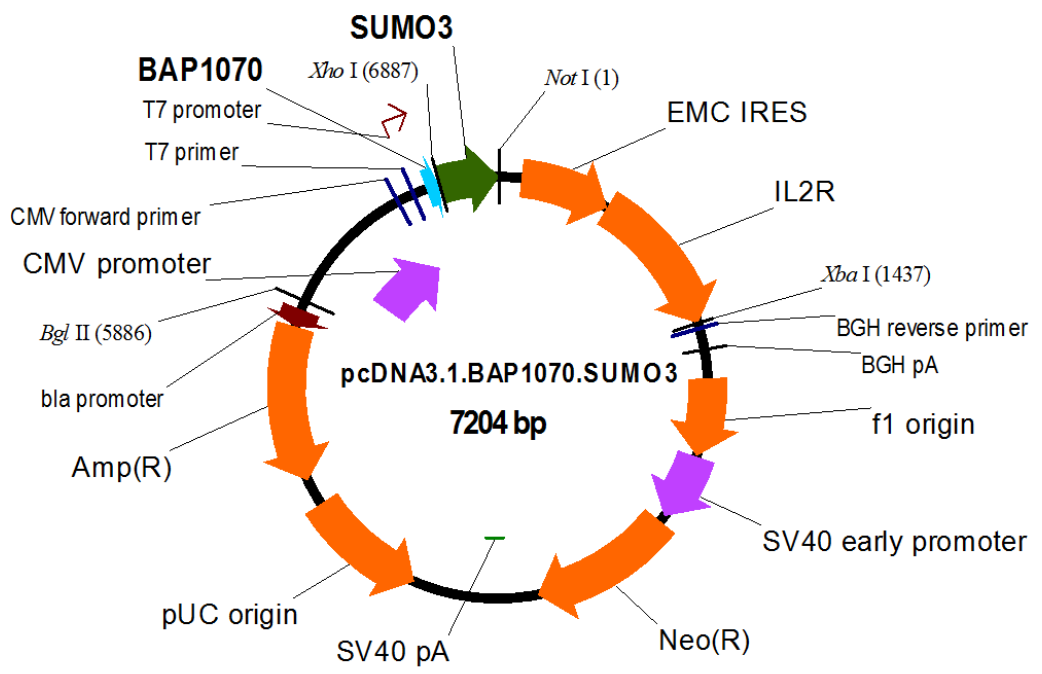

Construct was obtained on the basis of commercial plasmid pcDNA3.1(+) with CMV promoter [22].

Fig. 2. Plasmid map of construct used in experiments for transfection in eukaryotic cells on example of vector, containing SUMO3 gene, fused with BAP 
Genetic construction containing genes of SUMO1 and SUMO3, they sequencing and analysis.

For experiments on in vivo protein-protein interactions, we designed two types of vectors: one for the expression of BAP-fused targets, and the other for BirA-fusion proteins, which contain the following elements (on Figure 2 the map of pcDNA3.1(+).BAP.SUMO3 is presented as an example, the map of pcDNA3.1(+).BAP.SUMO1 is identical except ORF, where it is SUMO1 instead of SUMO3):

- The ORF of the SUMO3 regulatory protein gene is $310 \mathrm{bp}$ and the molecular mass is $11.637 \mathrm{kDa}$ (The ORF of the SUMO1 regulatory protein gene is $303 \mathrm{bp}$ and the molecular mass is $11.557 \mathrm{kDa}$ ).

- BAP (Biotin Acceptor Peptide) - domain of the biotin acceptor peptide, which also contains a heptagistidine 7His-tag, to monitor or purify recombinant proteins, regardless of the presence of a biotin tag.

- CMV - Cytomegalovirus enhancer-promoter.

- EMC IRES (Encephalomyocarditis Internal Ribosome Entry Site) - a sequence of a bicistronic transcription element allowing the expression of two proteins from a single transcript.

- IL2R (Interleukin-2 Receptor) - selection marker.

- $A m p(R)$ - selection marker of ampicilline resistance gene.

To obtain plasmids that contain the SUMO1 and SUMO3 genes fused to the biotin acceptor peptide BAP, we designed and ordered the corresponding primers containing the restriction sites of XhoI from the $\mathrm{N}$-terminus and NotI from the C-terminus (experimental part). The sequences of these nucleotides were aligned with the UbC and SUMO gene using the online program (https://npsa-prabi.ibcp.fr/cgibin/npsa_automat.pl?page=/NPSA/npsa_clustalw.html), and the absence of the XhoI and NotI sites inside the gene was checked using the ChromasPro program.

The resulting primers were then used in PCR using the high fidelity Roche DNA polymerase Pwo to amplify the SUMO1 and SUMO3 genes. The amplified fragments as well as the CMV.BAP vector were digested with XhoI and NotI, separated on $0.8 \%$ agarose gel, stained with ethidium bromide, excised from the gel, and the DNA was separated from the agarose and ligated with T4 DNA ligase overnight at $4^{\circ} \mathrm{C}$. The ligation mix was used for bacterial transformation in Escherichia coli (DH5 alpha strain) and plated on LB agar plates containing ampicillin $(250 \mu \mathrm{g} / \mathrm{ml})$ according to the standard protocol [19]. The grown clones were selected for insertion of the SUMO1 and SUMO3 genes by XhoI and NotI control restriction. The PCR test showed the insertion of the required genes in all clones.

For the final verification of the correctness of molecular cloning, two clones were selected from the constructs containing BAP, of which plasmids were produced and their sequence was analyzed (figure 3). The primer pcDNA3.1-FP (5 'CTCTGGCTAACTAGAGAAC 3') was used for the sequence of the assay, which is the standard primer for this vector. Moreover, the pcDNA3.1-FP primer also allowed to read part of the BAP in plasmid pcDNA3.1 (+). BAP.SUMO.

Files in text or FASTA format obtained after sequencing were also compared with the online database NCBI Blast (http://blast.ncbi.nlm.nih.gov/Blast.cgi) for nucleotide and amino acid sequences. Based on the results of the analysis, the complete correspondence of these sequences was revealed.

SUMO $1 \mathrm{C}$ - terminus
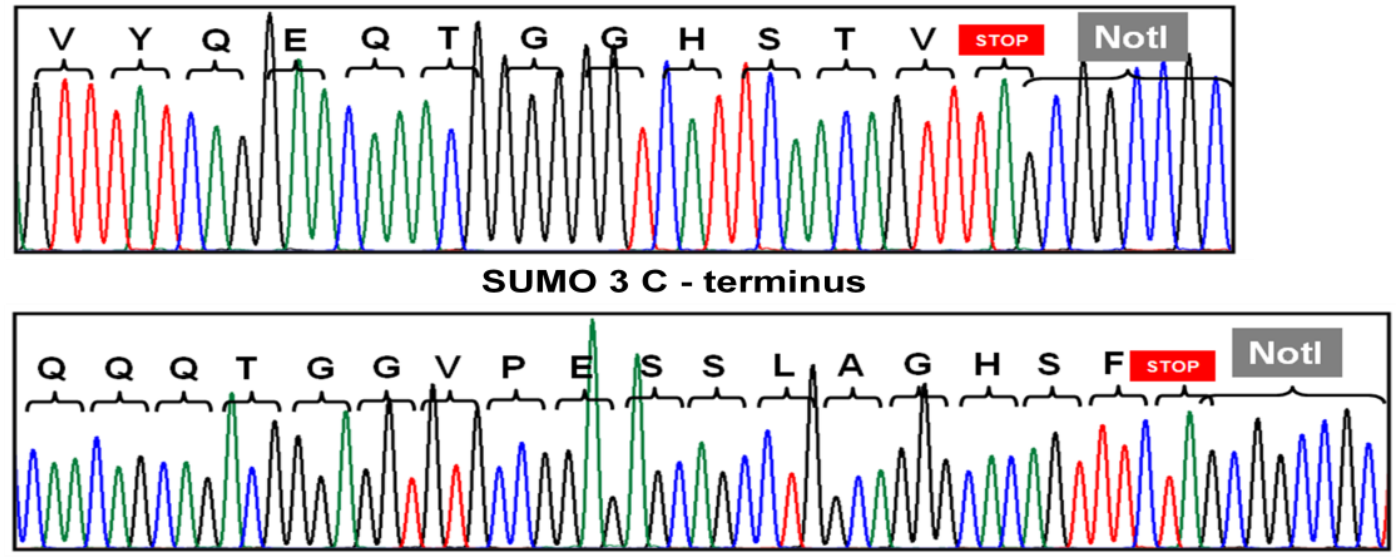

NotI - GCGGCCGC restriction site after TAG Stop-codon.

Fig. 3. Chromatograms of C-terminal regions of SUMO1 and SUMO3 proteins after sequencing

To verify the correct assembly of the resulting vectors, we performed various transfections in HEK293T cells: for example, the combined expression of recombinant proteins BAP-Ub+BirA-HP1 $\gamma$, BAP-SUMO1+BirA-HP1 $\gamma$, BAP-SUMO1+BirA-HP1 $\alpha$ and BAP-SUMO3+BirA-HP1 $\gamma$.

Expression of recombinant protein in HEK293T cells 
Figure 4A shows the results of immunoblotting of samples obtained from HEK293T cell nuclei. At the top of the figure, the membrane shows the expression level of BirA-HP1 $\gamma$ and BirA-HP1 $\alpha$ proteins, since the membrane is treated with antibodies to the polyhistidine fragment, which is also present between BirA and the reading frame of the proteins of interest (HP1 $\alpha$ and HP1 $\gamma$ ). The bottom of the figure shows a membrane treated with streptavidin, conjugated with HRP peroxidase. As in the case of expression of recombinant ubiquitin BAP-Ub (lanes 1 and 3 ) and recombinant BAP-SUMO1 protein (lanes 2 and 4), all the biotin-labeled proteins that are proximal sumoylated (ubiquitinated) proteins or protein partners of the proteins of interest are clearly visible. A similar picture is observed for the case of co-expression of BAP-SUMO3 + BirA-HP1 $\gamma$ (figure 4B). If we compare lanes 1, 2 (figure 4A) and 2 (figure 4B) we see different biotinylation patterns corresponding to different UBL-modified (Ub, SUMO1 and SUMO3) proteins which reflects real proximal protein network for POI (heterochromatin protein 1) in physiologically relevant context in the cell. In addition, there is some differences between SUMO1-modified proximal proteins between HP1 $\gamma$ and HP1 $\alpha$. For example, the band, corresponding to mass $39 \mathrm{kDa}$ (indicated by arrow on figure 4A) might be preferable SUMO1-modified interaction partner of HP1 $\alpha$ but not the HP1 $\gamma$. Further research will be continued to identify UBL-modified partners of heterochromatin protein 1.

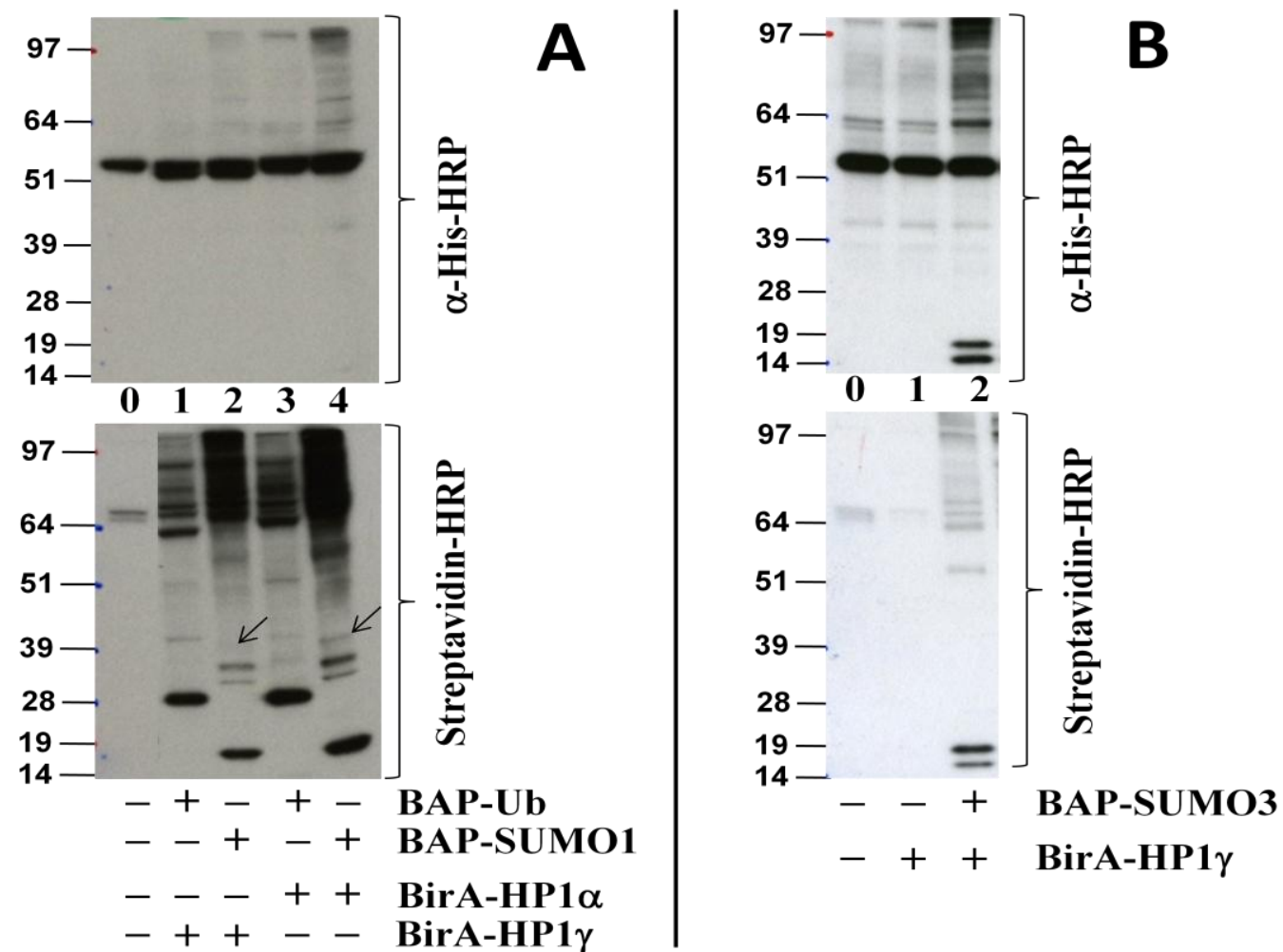

Top blot was treated with a-His-HRP, bottom blot was treated with streptavidin-HRP. 0 - control, calcium phosphate transfection without plasmid. Biotin pulse $30 \mathrm{~min}$. Arrows show band (or position on gel) about $39 \mathrm{kDa}$ which is probable SUMO1-modified interaction partner of HP1 $\alpha$ but not of HP1 $\gamma$.

Fig. 4. Biotinylation levels on Western blot of ubiquitinated (A) and sumoylated (A and B) proteins, interacting with protein of interest BirA-HP1 $\gamma$ and BirA-HP1 $\alpha$

\section{CONCLUSION}

Thus, based on the results of the experiments, two new vectors containing the human SUMO1 and SUMO3 gene, conjugated with the peptide acceptor of biotin BAP were obtained. The constructed plasmids pcDNA3.1 (+), BAP.SUMO1 and pcDNA3.1 (+). BAP.SUMO3 provided a high level of expression of recombinant BAP-SUMO1 and BAP-SUMO3 proteins sufficient for studies related to the quantitative evaluation of its expression in eukaryotic cells and study of protein-protein interactions in vivo.

\section{Aknowledgement}

This work was supported by the Ministry of Education and Science of the Republic of Kazakhstan under the project 1804/GF4 "New approaches for the study and quantification of in vivo ubiquitination, based on the proximity utilizing biotinylation" for 2015-2017 (State registration number 0115RK01802). The authors are grateful to the head of the Laboratory of Applied Genetics Alexander Shevtsov for his assistance in sequencing the plasmid 
constructs, as well as to the staff of the organic synthesis laboratory of the National Center for Biotechnology for the synthesis of primers.

\section{REFERENCES}

1. Hochstrasser M. Origin and function of ubiquitin-like proteins. Nature, 2009, vol. 458, pp. 422-429. doi: 10.1038/nature07958.

2. Golebiowski F. Matic I., Tatham M.H., Cole C., Yin Y., Nakamura A., Cox J., Barton G.J., Mann M., Hay R.T. System-wide changes to SUMO modifications in response to heat shock. Sci. Signal., 2009, vol. 2 , ra24. doi: 10.1126/scisignal.2000282.

3. Hendriks I.A. D'Souza R.C., Yang B., Verlaan-de Vries M., Mann M., Vertegaal A.C. Uncovering global SUMOylation signaling networks in a site-specific manner. Nat. Struct. Mol. Biol., 2014, vol. 21, pp 927-936. doi: 10.1038/nsmb.2890.

4. Schimmel J., Eifler K., Sigursson J.O., Cuijpers S.A., Hendriks I.A., Verlaan-de Vries M., Kelstrup C.D., Francavilla C., Medema R.H., Olsen J.V., Vertegaal A.C. Uncovering SUMOylation dynamics during cell-cycle progression reveals FoxM1 as a key mitotic SUMO target protein. Mol. Cell., 2014, vol. 53, pp 1053-1066. doi: 10.1016/j.molcel.2014.02.001.

5. Hendriks I.A., Vertegaal A.C. A comprehensive compilation of SUMO proteomics. Nat. Rev. Mol. Cell Biol., 2016, vol. 17, no. 9, pp. 581-595. doi: 10.1038/nrm.2016.81.

6. Geiss-Friedlander R., Melchior F. Concepts in sumoylation: a decade on. Nat. Rev. Mol. Cell Biol., 2007, vol. 8, pp. 947-956. doi: 10.1038/nrm2293.

7. Flotho A. and Melchior F. Sumoylation: A Regulatory Protein Modification in Health and Disease. Annu. Rev. Biochem., 2013, vol. 82, pp. 357-385. doi: 10.1146/annurev-biochem-061909-093311.

8. Ulrich H.D., Walden H. Ubiquitin signalling in DNA replication and repair. Nat. Rev. Mol. Cell Biol., 2010, vol. 11, pp. 479-489. doi: 10.1038/nrm2921.

9. Hickey C.M., Wilson N.R., Hochstrasser M. Function and regulation of SUMO proteases. Nat. Rev. Mol. Cell Biol., 2012, vol. 1, pp. 755-766. doi: 10.1038/nrm3478.

10. Jackson S.P., Durocher D. Regulation of DNA damage responses by ubiquitin and SUMO. Mol. Cell., 2013, vol. 49, pp. 795-807. doi: 10.1016/j.molcel.2013.01.017.

11. Eifler K., Vertegaal A.C. Mapping the SUMOylated landscape. FEBS J., 2015, vol. 282, pp. 3669-3680. doi: $10.1111 /$ febs.13378.

12. Eifler K., Vertegaal A.C. SUMOylation-mediated regulation of cell cycle progression and cancer. Trends Biochem. Sci., 2015, vol. 40, pp. 779-793. doi: 10.1016/j.tibs.2015.09.006.

13. Kessler J.D., Kahle K.T., Sun T., et al. A SUMOylation-dependent transcriptional subprogram is required for Myc-driven tumorigenesis. Science, 2012, vol. 335, pp. 348-353. doi: 10.1126/science.1212728.

14. Lee Y.J., Hallenbeck J.M. SUMO and ischemic tolerance. Neuromolecular Med., 2013, vol. 15, pp. 771781. doi: 10.1007/s12017-013-8239-9.

15. Wang Y., Dasso M. SUMOylation and deSUMOylation at a glance. J. Cell Sci., 2009, vol. 122, pp. 42494252. doi: $10.1242 /$ jcs.050542.

16. Becker J., Barysch S.V., Karaca S., et al. Detecting endogenous SUMO targets in mammalian cells and tissues. Nat. Struct. Mol. Biol., 2013, vol. 20, pp. 525-531. doi: 10.1038/nsmb.2526.

17. Matic I. van Hagen M., Schimmel J., Macek B., et al. In vivo identification of human small ubiquitin-like modifier polymerization sites by high accuracy mass spectrometry and an in vitro to in vivo strategy. Mol. Cell. Proteomics., 2008, vol. 7, pp. 132-144. doi: 10.1074/mcp.M700173-MCP200.

18. Tatham M.H. Jaffray E., Vaughan O.A., Desterro J.M., Botting C.H., Naismith J.H., Hay R.T. Polymeric chains of SUMO-2 and SUMO-3 are conjugated to protein substrates by SAE1/SAE2 and Ubc9. J. Biol. Chem., 2001, vol. 276, pp. 35368-35374. doi:10.1074/jbc.M104214200.

19. Sambrook J., Fritsch E.F. and Maniatis T. Cold Spring Harbor Laboratory Press, Cold Spring Harbor, NY, 1989, no. 1, 626 pp.

20. Graham F.L., van der Eb A.J. A new technique for the assay of infectivity of human adenovirus 5 DNA. Virology, 1973, vol. 52, no. 2, pp. 456-467. PMID: 4705382.

21. Higgins S.J., Hames B.D. Protein Expression. A practical approach. Oxford University Press, 1999,282 p.

22. Kulyyassov A., Shoaib M., Pichugin A., Kannouche P., Ramanculov E., Lipinski M., Ogryzko V. PUBMS: a mass spectrometry-based method to monitor protein-protein proximity in vivo. J. Proteome Res., 2011 , vol. 10, no. 10, pp. 4416-4427. doi: 10.1021/pr200189p.

23. Shoaib M., Kulyyassov A., Robin C., Winczura K., Tarlykov P., Despas E., Kannouche P., Ramanculov E., Lipinski M., Ogryzko V. PUB-NChIP - "in vivo biotinylation" approach to study chromatin in proximity to a protein of interest. Genome Research., 2013, vol. 23, no. 2, pp. 331-340. doi:10.1101/gr.134874.111.

24. Kulyyassov A.T., Zhubanova G.S., Ramanculov E.M., Ogryzko V.V. Method of quantitative evaluation of heterochromatin protein HP1 interactions in vivo. Biotechnology. Theory and practice, 2014, no. 1, pp. 17-27. doi: 10.11134/btp.1.2014.3. 
25. Kulyyassov A.T., Zhubanova G.S., Ramanculov E.M., Ogryzko V.V. Cloning and Expression of a Recombinant Protein of Human Ubiquitin Fused with a Biotin Acceptor Peptide. Biotechnology. Theory and practice, 2015, no. 4, pp. 38-46. doi: 10.11134/btp.4.2015.5. 